\title{
Fuzzy Synthetic Evaluation on Knitted Fabric's Subjective Comfort Sensations
}

\author{
Min Li, Dongping Li, Weiyuan Zhang, Yanxia Zhao \\ College of Fashion, Donghua University, Shanghai 200051, P. R. China
}

\begin{abstract}
Different kinds of knitted fabric vest are chosen as underwear samples made of a novel pearl - cellulose blend fiber and other functional fibers including Modal, milk fiber, Richcel, Dupont C, Tencel, cotton, viscose etc. Then subjective experiment with four stages is taken by strictly controlling the test condition, wearers' selection and training, questionnaire's design to test the comfort properties of underwear. Finally, based on fuzzy set theory, the comprehensive comfort sensations of these fabrics in different wear conditions are analyzed and evaluated.
\end{abstract}

Keywords: Fuzzy set theory, Subjective evaluation, Knitted fabric, Comfort sensations

\section{Introduction}

Comfort is one of the most important attributes of clothing demanded by modern consumers [1]. Thermal comfort means that clothing climate is in comfort state through clothing system regulating heat and moisture transfer between body and environmental conditions. Fanger defines three conditions for a person to be in thermal comfort: the body is heat balance; sweat rate is within comfort limits; and mean skin temperature is within comfort limits [2]. However comfort is a very subjective, vague and complex feeling, which involves multidimensional factors. LaMotte stated that physical comfort might be greatly influenced by the tactile and thermal sensations [3]. Li stated that comfort was a state of multiple interactions among psychological sensations that were determined by physical, psychological and environmental factors [4].

Wear tests or wearer trials are commonly used to evaluate the garments subjectively. Wearer trial is rated as an end-use performance test to collect the subjective comfort sensations of the wearers [5]. It is a relatively expensive, inconsistent and unsafe but realistic and comprehensive evaluation [6]. However, comfort is difficult to measure by objective approaches because the subjective assessment as human would become accustomed to different conditions gradually, so wearer trials are also preferable.
Based on fuzzy set theory, this study is focused on the subjective measurement of the heat and moisture transfer properties of knitted fabrics made of a novel pearl - cellulose blend fiber and other functional fibers including Modal, milk fiber, Richcel, Dupont C, Tencel, cotton, viscose etc.

\section{Experimental}

\subsection{Fabric samples}

\begin{tabular}{c|l|c|c|c}
\hline $\begin{array}{c}\text { Sample } \\
\text { No. }\end{array}$ & $\begin{array}{l}\text { Composition } \\
\text { of } \\
\text { raw material }\end{array}$ & $\begin{array}{c}\text { Material } \\
\text { Proportion } \\
(\%)\end{array}$ & $\begin{array}{c}\text { Thickness } \\
(\mathrm{mm})\end{array}$ & $\begin{array}{c}\text { Mass per } \\
\text { unit area } \\
\left(\mathrm{g} / \mathrm{m}^{2}\right)\end{array}$ \\
\hline 1 & Viscose & 100 & 0.86 & 279.32 \\
\hline 2 & PC fiber & 100 & 0.85 & 243.29 \\
\hline 3 & Milk fiber & 100 & 0.73 & 200.34 \\
\hline 4 & Richcel & 100 & 0.77 & 179.15 \\
\hline 5 & Tencel & 100 & 0.56 & 259.92 \\
\hline 6 & Modal & 100 & 0.75 & 207.15 \\
\hline 7 & Cotton & 100 & 0.98 & 236.32 \\
\hline 8 & $\begin{array}{l}\text { PC fiber/ } \\
\text { Tencel/ } \\
\text { Modal }\end{array}$ & $30 / 40 / 30$ & 0.69 & 199.29 \\
\hline 9 & $\begin{array}{l}\text { PC } \\
\text { filament }\end{array}$ & 100 & 0.63 & 209.65 \\
\hline 10 & $\begin{array}{l}\text { Viscose } \\
\text { filament }\end{array}$ & 100 & 0.63 & 227.78 \\
\hline 11 & $\begin{array}{l}\text { PC } \\
\text { fiber/cotton }\end{array}$ & $50 / 50$ & 0.97 & 230.83 \\
\hline 12 & $\begin{array}{l}\text { Modal/ } \\
\text { cotton }\end{array}$ & $50 / 50$ & 0.94 & 240.82 \\
\hline
\end{tabular}

Table 1: The parameter of fabric samples.

Pearl - cellulose blend fiber Pearl fiber (abbreviation: PC fiber) is a novel functional cellulose fiber that is developed by Donghua University and Shanghai New Spinning Research Center. Its high technology is plus nano pearl powders during the spinning process of viscose fiber, so pearl corpuscles are evenly distributed on the surface of fiber and wealthy of amino acid and trace elements. Its fabric was proved to be good to skin and bear with excellent functional performance including far infrared emission, 
ultraviolet radiation protection etc. Knitted fabric made of functional fiber is mainly developed for underwear. Therefore, plain jersey stitch is adopt in this study, which is the most easy single face structure and suitable for underwear and summer clothing. The parameter of samples is showed in Table 1.

All fabrics are made to vest with following size: L (long)-62, B (bust)-78, W (waist)-72, BL (band long)-22.

\subsection{Subjects}

Nine female volunteers aged between 24 26 participated as human subjects in the wear trial. All subjects were considered healthy and exercised regularly. Each subject tested one vest sample at one time. The details of the nine subjects are shown below.

\begin{tabular}{c|c|c|c}
\hline $\begin{array}{c}\text { Bust Girth } \\
(\mathrm{cm})\end{array}$ & $\begin{array}{c}\text { Waist Girth } \\
(\mathrm{cm})\end{array}$ & $\begin{array}{c}\text { Height } \\
(\mathrm{cm})\end{array}$ & $\begin{array}{c}\text { Weight } \\
(\mathrm{kg})\end{array}$ \\
\hline $82 \pm 4$ & $64 \pm 4$ & $160 \pm 5 \mathrm{~cm}$ & $50 \pm 2 \mathrm{~kg}$ \\
\hline \multicolumn{3}{c}{ Table 2: Mean and standard deviation of subjects' } \\
demographic information
\end{tabular}

\subsection{Wear trial and questionnaire}

The test conditions were controlled at temperature $(25 \pm 1){ }^{\circ} \mathrm{C}$, relative humidity $(65 \pm 3) \%$ and with an air velocity varying below $0.1 \mathrm{~m} / \mathrm{s}$. Subjects were invited to have a pre-trial before formal trials, to obtain training and understanding of the questions and the procedures involved.

Each trial has 4 stages. In stage 1 the subjects were required to change the test garments with nothing on the top and cotton pajama trousers on the bottom. Then they had a rest in the test garments and environment prior to the testing for 10 minutes, to get equilibrium. And then in stage 2 the subject would walk on a treadmill (IMPEX) for 10 minutes with the speed of $2.0 \mathrm{~km} /$ hour. In stage 3 the subject was required to run on the treadmill (IMPEX) for 10 minutes with the speed of $6.5 \mathrm{~km} /$ hour. In stage 4 they have a rest for anther 10 minutes.

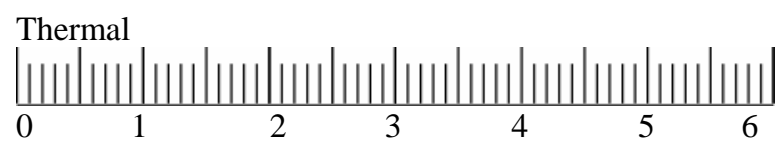

0-Too cold, 1-Cold, 2-Cool, 3-Moderate, 4- Warm, 5-Hot, 6-Too hot

Fig.1: The seven-main-point scale for measuring the sensation of thermal

During each trial, the subject was asked to fill in a questionnaire by rating the 9 sensations (thermal, moisture, clinging, stifling, rough, soft, drape, prickle, tight) and overall comfort on a seven-main-point scale in 10, 20, 30, 40minutes. Fig. 1 shows sample of the scale. In the scale too cold is equal to 0 , moderate is equal to 3 , and too hot is equal to 6 . The wearer trials were repeated by wearing different samples.

\section{Results and discussion}

The average of nine subjects' data was calculated and Table 3 shows the result of stage 1 . Results of other stages are omitted here.

\begin{tabular}{|c|c|c|c|c|c}
\hline No & Thermal & Moisture & Clinging & Stifling & Rough \\
\hline 1 & 2.61 & 2.67 & 2.24 & 2.72 & 3.54 \\
\hline 2 & 2.74 & 2.78 & 2.91 & 3.03 & 3.83 \\
\hline 3 & 3.55 & 2.85 & 2.88 & 3.01 & 3.23 \\
\hline 4 & 3.19 & 2.94 & 3.24 & 2.70 & 4.06 \\
\hline 5 & 1.79 & 2.96 & 2.04 & 2.48 & 4.65 \\
\hline 6 & 2.97 & 3.00 & 2.87 & 2.81 & 3.73 \\
\hline 7 & 3.24 & 2.93 & 2.76 & 3.83 & 2.43 \\
\hline 8 & 2.98 & 3.04 & 2.14 & 2.77 & 3.63 \\
\hline 9 & 2.14 & 2.95 & 2.24 & 2.55 & 4.09 \\
\hline 10 & 2.32 & 2.69 & 2.27 & 2.40 & 4.60 \\
\hline 11 & 3.41 & 3.47 & 3.43 & 3.28 & 3.18 \\
\hline 12 & 3.33 & 2.93 & 2.72 & 3.16 & 2.79 \\
\hline
\end{tabular}

Table 3: Data of subjective sensations (stage 1)

\begin{tabular}{|c|c|c|c|c|c}
\hline No & Soft & Drape & Prickle & Tight & Overall \\
\hline 1 & 3.84 & 3.73 & 3.37 & 4.01 & 3.98 \\
\hline 2 & 4.07 & 4.72 & 3.90 & 4.12 & 3.89 \\
\hline 3 & 3.47 & 3.58 & 3.53 & 4.03 & 3.63 \\
\hline 4 & 3.50 & 3.77 & 3.75 & 3.94 & 3.90 \\
\hline 5 & 4.05 & 4.17 & 4.18 & 3.30 & 4.32 \\
\hline 6 & 3.91 & 4.06 & 3.58 & 4.10 & 3.67 \\
\hline 7 & 2.50 & 2.88 & 2.90 & 2.55 & 3.08 \\
\hline 8 & 4.03 & 3.66 & 3.67 & 3.48 & 3.76 \\
\hline 9 & 4.33 & 4.35 & 4.50 & 3.82 & 4.21 \\
\hline 10 & 3.90 & 5.03 & 4.64 & 3.75 & 4.25 \\
\hline 11 & 3.84 & 3.35 & 3.20 & 3.27 & 3.29 \\
\hline 12 & 3.74 & 3.19 & 3.43 & 3.80 & 3.46 \\
\hline
\end{tabular}

(Table 3 continued)

\subsection{Test of Kendall's coefficient of concordance}

The data process is done on SPSS data processing system. First, the validity of subjective experimental results is examined by using Kendall coordination coefficient of pair's samples. The Kendall's coefficient of concordance $(W)$ is used for measuring agreement among $\mathrm{k}$ sets of species rating values. $W$ is an index of the divergence of the actual agreement shown in the data from the possible perfect agreement. Values of $W$ can range from 0 to 1 , with 0 indicating perfect disagreement, and 1 indicating perfect agreement (Landis \& Koch, 1977) [7]. 
Take $k$ columns with $n$ items in each and rank each column from 1 to $n$. The null hypothesis is that the rankings disagree.

Compute a sum of ranks $S R_{i}$ for each row. Then $S=\sum(S R)^{2}-n(\overline{S R})^{2}$, where $\overline{S R}=\frac{(n+1) k}{2}$ is the mean of the $S R_{i}$ s. If $H_{0}$ is disagreement, $S$ can be checked against a table for this test. If $S>S_{\alpha}$ reject $H_{0}$. For $n$ too large for the table use $\chi^{2(n-1)}=k(n-1) W=\frac{S}{1 / 12 k n(n+1)} \quad, \quad$ where $W=\frac{S}{1 / 12 k^{2}\left(n^{3}-n\right)}$ is the Kendall Coefficient of Concordance and must be between 0 and 1 .

\begin{tabular}{c|l|c|c|c|c}
\hline \multicolumn{2}{c|}{ Index } & \begin{tabular}{c} 
Stage \\
\multicolumn{2}{c|}{}
\end{tabular} & $\begin{array}{c}\text { Stage } \\
2\end{array}$ & $\begin{array}{c}\text { Stage } \\
3\end{array}$ & $\begin{array}{c}\text { Stage } \\
4\end{array}$ \\
\hline \multirow{2}{*}{ Thermal } & $W$ & .368 & .210 & .203 & .205 \\
\cline { 2 - 6 } & $S$ & .000 & .036 & .044 & .042 \\
\hline \multirow{2}{*}{ Moisture } & $W$ & .208 & .205 & .220 & .203 \\
\cline { 2 - 6 } & $S$ & .038 & .041 & .026 & .045 \\
\hline \multirow{2}{*}{ Clinging } & $W$ & .267 & .204 & .214 & .119 \\
\cline { 2 - 6 } & $S$ & .006 & .043 & .032 & .049 \\
\hline \multirow{2}{*}{ Stifling } & $W$ & .388 & .212 & .200 & .287 \\
\cline { 2 - 6 } & $S$ & .000 & .033 & .049 & .003 \\
\hline \multirow{2}{*}{ Rough } & $W$ & .596 & .496 & .273 & .300 \\
\cline { 2 - 6 } & $S$ & .000 & .000 & .005 & .002 \\
\hline \multirow{2}{*}{ Soft } & $W$ & .293 & .243 & .202 & .207 \\
\cline { 2 - 6 } & $S$ & .002 & .012 & .045 & .039 \\
\hline \multirow{2}{*}{ Drape } & $W$ & .360 & .522 & .428 & .442 \\
\cline { 2 - 6 } & $S$ & .000 & .000 & .000 & .000 \\
\hline \multirow{2}{*}{ Prickle } & $W$ & .486 & .343 & .278 & .394 \\
\cline { 2 - 6 } & $S$ & .000 & .000 & .004 & .000 \\
\hline \multirow{2}{*}{ Tight } & $W$ & .416 & .362 & .285 & .264 \\
\cline { 2 - 6 } & $S$ & .000 & .000 & .003 & .006 \\
\hline \multirow{2}{*}{ overall } & $W$ & .442 & .342 & .229 & .349 \\
\cline { 2 - 6 } & $S$ & .000 & .000 & .000 & .000 \\
\hline
\end{tabular}

Table 4: Test result of Kendall's coefficient of concordance

We could see from Table 4, in all stages, $\mathrm{S}<0.05$. So reject null hypothesis. The result shows although there are differences between wearers, their grades are consistency. The data meets the requirement of further analysis.

\subsection{Fuzzy set theory}

From the data above, we could see that they only separately reflect each sample's comfort sensation properties. Furthermore, all these aspects' performances affect clothing's comfort sensations. Only one or two index is not enough to give synthetic evaluation about sample's comfort. The total quantity of data is little, the rule is still not clear, so it is hard to induce effective conclusion by mathematical statistic method. Fuzzy set theory has some advantages in identifying and approximating any uncertain nonlinear dynamic systems defined on the compact set with arbitrary accuracy, drawing similarities from a vast amount of data, and making use of information of data and language. Therefore, fuzzy set theory introduced by Lotfi A. Zadeh (1965) is introduced to give subjective evaluation [8].

\subsection{Fuzzy evaluation on subjective sensations}

Comprehensive evaluation is concluded on the comfort sensations of twelve vests made of different fabrics of four stages by adopting DPS data system [9].

Firstly, set up set of evaluation object $D=\{$ Sample 1,Sample 2,Sample 3,Sample 4,Sample 5, Sample 6, Sample 7, Sample 8, Sample 9, Sample 10, Sample 11, Sample 12\}

Secondly, set up set of factors of evaluation object $U=\{$ thermal, moisture, clinging, stifling, rough, soft, drape, prickle, tight, overall $\}$

Thirdly, set up set of comment $\mathrm{V}$ and give value $\mathrm{Q}=\{0,1,2,3,4,5,6\}$

Fourthly, decide the according weighted value of factors.

Then, data are processed on DPS platform. Take the overall comfort sensations as mother element, other index as daughter elements, set up mother matrix and daughter matrix. Original data are transferred by standard method. When calculate relative coefficient, take distinguish coefficient $\rho=0.1$. Calculate relative coefficient of index first, and then get weight coefficient of every matrixes with normalization. Results are showed in Table 5.

\begin{tabular}{c|c|c|c|c}
\hline Index & $\begin{array}{c}\text { Therma } \\
\mathrm{l}\end{array}$ & $\begin{array}{c}\text { Moistur } \\
\mathrm{e}\end{array}$ & $\begin{array}{c}\text { Clingin } \\
\mathrm{g}\end{array}$ & Stifling \\
\hline $\begin{array}{c}\text { Relative } \\
\text { value }\end{array}$ & 0.288 & 0.353 & 0.258 & 0.359 \\
\hline $\begin{array}{c}\text { Weight } \\
\text { coefficie } \\
\text { nt }\end{array}$ & 0.074 & 0.091 & 0.066 & 0.092 \\
\hline
\end{tabular}

Table 5: Weight coefficient (Stage 1).

\begin{tabular}{c|c|c|c|c|c}
\hline Index & Rough & Soft & Drape & Prickle & Tight \\
\hline $\begin{array}{c}\text { Relative } \\
\text { value }\end{array}$ & 0.647 & 0.431 & 0.498 & 0.647 & 0.389 \\
\hline $\begin{array}{c}\text { Weight } \\
\text { coefficient }\end{array}$ & 0.167 & 0.111 & 0.128 & 0.167 & 0.100 \\
\hline
\end{tabular}

(Table 5 continued)

We could see from Table 5, in the stage of static, prickle sensation, rough sensation and drape sensation are the important factors affecting wearer's comfort sensations. In the stage of static, people are very sensitive to the tiny stimulus by skin. And it is not apparent that moisture transmission, air permeability 
affect overall comfort sensation since people haven't any movement.

Calculate the relative matrix by DPS, the results are as following.

Stage $1: \quad \mathrm{B}=(0.7018,0.6111,0.7656$, $0.6834,0.5037,0.7287,0.8753,0.8039$, $0.5002,0.4752,0.8124,0.6849$ )

According to maximum subordination principle, comfort sensation from best to good to not good are: cotton, PC fiber/cotton, PC fiber/ Tencel/ Modal, Milk fiber, Modal, Viscose, Modal/ cotton, Richcel, PC fiber, Tencel, PC filament, Viscose filament.

The result of stage 2 to stage 4 is following.

Stage 2: $\mathrm{B}=(0.8229,0.6605,0.8102$, $0.7182,0.5638,0.7892,0.8632,0.8095$, $0.6193,0.58250 .8082,0.7863$ )

According to maximum subordination principle, comfort sensation from best to good to not good are: cotton, Viscose, Milk fiber, PC fiber/ Tencel/ Modal, PC fiber/cotton, Modal, Modal/ cotton, Richcel, PC fiber, PC filament, Viscose filament, Tencel.

Stage 3: $B=(0.5717,0.5440,0.5293$, $0.5165,0.5129,0.5087,0.5994,0.5153$, $0.5686,0.5710,0.5007,0.5036$ )

According to maximum subordination principle, comfort sensation from best to good to not good are: cotton, Viscose, Viscose filament, PC filament, PC fiber, Milk fiber, Richcel, PC fiber/ Tencel/ Modal, Tencel, Modal, Modal/ cotton, PC fiber/cotton.

Stage 4: $B=(0.8468,0.6659,0.8722$, $0.8327,0.7142,0.8146,0.8793,0.8322$, $0.6085,0.6454,0.8865,0.8812$ )

According to maximum subordination principle, comfort sensation from best to good to not good are: PC fiber/cotton, Modal/ cotton, cotton, Milk fiber, Viscose, Richcel, PC fiber/ Tencel/ Modal, Modal, Tencel, PC fiber, Viscose filament, PC filament.

\section{Conclusions}

Based on subjective experiments, the comfort sensations of underwear made of different functional fibers are tested. Although there are differences between wearers, their grades are proved to be consistency by test of Kendall's coefficient of concordance.

Fuzzy synthetic evaluation of subjective sensations is following.

Stage 1 - rest: In the stage of rest before sports, the comprehensive comfort sensation of knitted fabric made of PC blended fiber are better than that of Modal, Richcel, but worse than viscose fiber.

Stage 2 - walking: In the stage of light sports, the comprehensive comfort sensation of knitted fabric made of PC blended fiber are descending, but still better than that of Modal, Richcel, meanwhile worse than viscose fiber.

Stage 3 - running: In the stage of running state, the comprehensive comfort sensation of knitted fabric made of pure PC fiber are better than that of Modal, Richcel. The worst one is PC fiber/cotton.

Stage 4 - rest: In the stage of rest after sports, the comprehensive comfort sensation of knitted fabric made of PC blended fiber are worse than that of viscose, Modal. The worst one of comfort sensations is PC fiber filament underwear.

In general, comfort sensation of cotton and PC blended fiber are better in four stages.

\section{Acknowledgement}

This work is partially supported by Shanghai Municipal Education Commission (Grant No. 03YQHB073)

\section{References}

[1] Y. Li, Clothing Comfort and Development of Products, China Textile Press, Beijing, 2002.

[2] Fanger, P.O., Thermal Comfort, Danish Technical Press, Copenhagen, 1970.

[3] R.H. LaMotte, Psychophysical and Neuropsychological Studies of Tactile Sensibility, The Fiber Society, Inc. Clothing ComfortInteraction of Thermal, Ventilation, Construction and Assessment Factors, Ann Arbor Michigan, 1977.

[4] Y. Li, The Science of Clothing Comfort: A critical Appreciation of Resent Development, Textile Institute International, Manchester, 2001.

[5] R.S. Merkel, and I.B. Miller, Recommendations for Investigating the Degree of Correlation Between Lab Tests and Wear Tests, Textile Chemist and Colorist, 19(4): 23-25, 1987.

[6] K.C. Parsons, Human Thermal Environments The effects of hot, moderate and cold environments on human health, comfort and performance, Taylor \& Francis, London, 1993.

[7] W.P. Zhang, H.Y. Chen, Data Statistic Analysis and Application of SPSS12.0, People Post Press, Beijing, 2006.

[8] A.Zadeh Lotfi, Fuzzy sets, Information and Control, 8: 338-353, 1965.

[9] Q.Y. Tang, DPS Data Processing SystemDesign of Experimental, Processing of Data, Simulation Analysis, Science Press, Beijing, 2006. 